\title{
SOMATIC CROSSING-OVER IN ANTIRRHINUM MAJUS
}

\author{
BRIAN J. HARRISON and ROSEMARY CARPENTER \\ John Innes Institute, Colney Lane, Norwich NR4 7UH
}

Received 23.viii.76

\begin{abstract}
SUMMARY
Many aberrant somatic sectors on the corollas of heterozygous Antirrhinum majus can be related to a number of genetic causes while twin-spots are attributed to somatic crossing-over, hitherto, considered a relatively rare occurrence in higher plants. The administration of caffeine increases the frequency of single aberrant sites and also of twin-spots. The inclusion of the unstable genes nivea-recurrens and pallida-recurrens has no effect on the frequency of twin-spots. Homozygosity following somatic crossing-over is presumed for several loci and some evidence is presented for deficiency aberrations. The usc of precise precursors in the biosynthetic pathway to anthocyanidin formation provided confirmatory evidence for the identification of the genes involved in the somatic aberrations.
\end{abstract}

\section{INTRODUCTION}

MosaIC regions on various parts of plants have been recorded in a range of species and related to several genetic causes (Jones, 1937). Mosaics have also been identified and investigated in Drosophila (Stern, 1936), the domestic fowl (Serebrovsky, 1925), housefly (Nöthiger and Dübendorfer, 1971) and the mouse (Gruneberg, 1966); but it is particularly in higher plants that renewed interest and critical analyses have recently established the genetic causes with more confidence. The somatic variations reported in Nicotiana tabacum (Carlson, 1974; Dulieu, 1975), Glycine max (Vig, 1975), Tradescantia (Mericle and Mericle, 1967), Lycopersicum esculentum Ross and Holm, 1960; Christianson, 1975), Arabidopsis thaliana (Hirono and Rédei, 1965), Crepis capillaris (Dubinin and Nemtseva, 1969), Gossypium sp. (Barrow, Chaudhari and Dunford, 1973; Barrow and Dunford, 1974), Pisum sativum (Blixt, 1972) and Salvia splendens (Hendrychova-Tomkova, 1964) have been variously attributed to point mutation, gene conversion, non-disjunction, translocation, deletion and somatic crossing-over. The appearance of twinspots (fig. 1) in heterozygotes is diagnostic of either non-disjunction or crossing-over; the two components would be expected to be of dissimilar size because of chromosome imbalance if initiated by non-disjunction but could be of similar size if the two components were homozygous and resulted from somatic crossing-over.

Analysis of twin-spots by Vig $(1973,1975)$ and Evans and Paddock (1976) in Glycine max and Nicotiana tabacum, the in vitro culture of twin-spot components in Nicotiana by Deshayes and Dulieu (1974) and Carlson (1974) and the mutational work on the petals and stamen hairs of Tradescantia by Mericle and Mericle (1967) and Christianson (1975) show that crossingover is certainly involved in at least some aberrant somatic sites. However, if only one component of the twin establishes a cell lineage or if only one homozygote is recognisable against the heterozygous background then twin- 
spots will not be observed although the aberrant site may be the result of crossing-over.

The prescnt study on somatic variants in Antirrhinum majus provides further evidence for such aberrations in plants and suggests that somatic crossing-over is one of the main causes. Chemical agents, such as mitomycin and caffeine, which affect the frequency of crossing-over were advantageously used by Vig (1975) in Glycine max and their relationship to the production of twin-spots was substantiated. Mitomycin $\mathrm{C}$ was also found to increase the frequency of somatic crossing-over in fungi (Holliday, 1964). Caffeine has been shown to incrcase both point mutation and crossing-over in Glycine max and is considered, similarly with mitomycin, to allow the reunion of chromosome breaks, whereas puromycin causes segmental losses and no subsequent rejoining after breakage, with no associated increase in twin-spots (Vig, 1973).

In addition to the caffeine treated lines of Antirrhinum (heterozygous for several loci) a comparison was made of similar heterozygotes that also contained the unstable pallida-recurrens allele in hypostatic combinations in order to assess its effect on the production of somatic aberrations. At one time it had bccn considered possible that the mutability of the unstable gene was related to meiotic and mitotic crossing-over. It was shown that there was no evidence for this happening meiotically (Harrison and Fincham, 1965) but the mitotic possibility was unresolved. Since Stern (1936) showed that somatic crossing-over occurs in male Drosophila there can be no extrapolation from meiotic to mitotic processes in this connection.

The utilisation of precise precursors to overcome genetic blocks in the biosynthetic pathway to anthocyanin production (Stickland and Harrison, 1974; Harrison and Stickland, 1974) has provided a technique for identification of the genetic block within a mosaic site of twin-spot component, provided that the area contains several hundrcd cells.

\section{Materials AND Methods}

The inbred Antirrhinum majus stocks incolorata, eosinea, nivea, nivea-recurrens and pallida-recurrens have been maintained at this Institute for many years and agree with the description given by Stubbe (1966). Fuller descriptions of the recurrens alleles are given in Harrison and Carpenter (1973). The plants were sown and grown in standardiscd John Innes composts and then either grown outside or in a glasshouse where the natural light was supplemented during the winter months with G.E.C. Solarcolour sodium lights.

The method of counting sitcs varied from (a) scoring every flower during the flowering season and recording every sitc on the facial surfaces of the corolla lobes to $(b)$ selecting certain plants and scoring all the sites on the facial surface of one upper lobe. The particular counting method is designated in the tables. The type of corolla lobe and surface chosen for counting is shown in close-up in fig. 6 .

The caffeine treatment was effected by the immersion of young developing inflorescences in either 0.25 per cent or 0.5 per cent aqueous solutions for 24 hours; the largest buds of the treated inflorescences were approximately $15 \mathrm{~mm}$ long. The temperature during treatment was glasshouse temperature which ranged during the tests from $10^{\circ} \mathrm{C}$ (night) to $24^{\circ} \mathrm{C}$ (day). Subsequent 
flower development in the glasshouse experienced a similar range of temperature.

The use and origin of anthocyanin precursors for the identification of somatic sites were as described in Stickland and Harrison (1974) and Harrison and Stickland (1974).

\section{Results}

(i) The effect of recurrens alleles on the frequency of somatic recombination

The effect on the incidence of putative somatic crossing-over and other genetic events by the inclusion of the highly mutable recurrens alleles of pallida and nivea was assessed in several heterozygous populations of Antirrhinum majus. Any influence of the recurrens alleles would appear from a comparison of the frequencies of twin-spots and single sites in the families incolorata $\times$ pallida-recurrens and incolorata crossed to the stable non-recurrens alleles pallida-tubocolorata, pallida-tincta and nivea : eosinea.

Single aberrant sites may result from a number of causes additional to the establishment of a single cell lineage from one component of a cross-over

TABLE 1

Flower pigmentation in various genotypes of Antirrhinum majus

Genotype

nivea/nivea

nivea/Nivea (niv/Niv)

Nivea/Nivea

incolorata/incolorata

incolorata/Incolorata (inc/Inc)

Incolorata/Incolorata

pallida-recurrens/pallida-recurrens

pallida-recurrens/ Pallida (pal-rec/Pal) pallida-tubocolorata/pallida-tubocolorata

pallida-tubocolorata/Pallida ( pal-tub/Pal) pallida-tubocolorata/pallida-recurrens

pallida-tincta/pallida-tincta pallida-tincta/pallida (Pal-tincta/Pal) eosinea/eosinea

eosinea/Eosinea (eos/Eos)
Phenotype of flower

acyanic (albino)

medium/dark magenta

dark magenta

acyanic (ivory)

medium magenta

dark magenta

flaked with pigment where pallida-recurrens mutates to Pallida

dark magenta

acyanic except for pigmented ring around base of corolla tube

dark magenta

flaked corolla and pale pigmented ring at base of corolla tube

acyanic, occasionally with pale flush

dark magenta

pelargonidin pigment (i.e. pink)

cyanidin pigment (i.e. magenta)

event potentially capable of producing a twin-spot. Twin-spots can, of course, only be identified when the gene involved is semi-dominant e.g. incolorata (see table 1 for gene expression).

A comparison of the two sets of data in table 2 shows that there was no significant effect of an unstable recurrens allele in the genotype on the frequency of single and twinned aberrant sites. There was a 10 -fold increase in the number of single sites over twinned; and, as stated earlier, the single sites could arise from a number of different genetic events.

Precise data regarding the position of centromeres and the loci of many genes is lacking in Antirrhinum majus. The comparison of non-rec and rec genotypes in table 2 is based on different sets of known heterozygous loci. 
TABLE 2

Frequencies of aberrant sites on flowers of non-recurrens and recurrens genotypes

\begin{tabular}{l}
$\quad$ Non-recurrens genotype \\
niv eos Inc \\
Niv Eos inc \\
niv Eos Inc pal-tub \\
\hline Niv Eos inc Pal \\
Eos inc Pal \\
Eos Inc pal-tincta \\
Eos inc Pal \\
\hline Eos Inc Pal \\
$\quad$ Recurrens genotype \\
Mean number of sites per flower \\
eos Inc pal-rec $\mathrm{L} \mu^{*}$ \\
Eos inc Pal \\
Eos Inc pal-rec $\mathrm{L} \mu^{*}$ \\
Eos inc Pal \\
oos Inc pal-rec $\mathrm{H}_{\mu} *$ \\
Eos inc Pal \\
Eos Inc pal-rec $\mathrm{H}_{\mu}^{*}$ \\
Eos inc Pal \\
Eos Inc pal-rec $\mathrm{vH} \mu^{*}$ \\
Eos inc Pal
\end{tabular}

Mean number of sites per flower
Aberrant sites $\uparrow /$ number of flowers

\begin{tabular}{cc} 
Twinned & Single \\
$11 / 2510$ & $132 / 2510$ \\
$9 / 11603$ & $215 / 11603$ \\
$19 / 13711$ & $131 / 13711$ \\
$8 / 7210$ & $66 / 7210$ \\
\hline $47 / 35034$ & $544 / 35034$ \\
$0 \cdot 0013$ & $0 \cdot 0155$ \\
$8 / 9212$ & $85 / 9212$ \\
$16 / 14854$ & $91 / 14854$ \\
$14 / 15324$ & $288 / 15324$ \\
$11 / 6973$ & $114 / 6973$ \\
$40 / 13886$ & $233 / 13886$ \\
\hline 0.0015 & $0 \cdot 0135$ \\
& \\
\hline
\end{tabular}

* $\mathrm{L} \mu, \mathrm{H} \mu, \mathrm{vH}_{\mu}$-low, high and very high mutation rate as described in Harrison and Fincham (1968).

+ Counts made macroscopically; they are lower than those recorded in tables 4, 6, 8, 9 and 10 which were made microscopically.

The comparison can only be approximate; for the non-rec set there was a mean of 2.8 known heterozygous genes per flower and for the rec genotypes the value was $2 \cdot 3$. The dissimilarity in known gene content together with accompanying unknown heterozygous genes affecting pigmentation can be expected to give some differences between the two sets of data which are in remarkably good agreement.

(ii) Meiotic crossing-over in pallida-recurrens heterozygotes

The original purpose of this test (Harrison and Fincham, 1965) was to assess any effect of crossing-over on the mutability of pal-rec to other more stable alleles in the series. The results are of interest here since it has already been shown in the previous section that no relationship between mitotic crossing-over and the presence of unstable pal-rec could be established. The converse is also shown, namely that no inhibition of meiotic crossing-over occurred when the unstable rec allele was included in the genotype; this is relevant when considering the possibility of an inhibiting effect occurring somatically. 
The closest available markers flanking the pal locus were Eluta (El) (dilution of flower pigment) and divaricata (div) (morphological restriction of face area).

Crosses were made of the type:

$$
\frac{\text { el pal-rec div }}{\text { El pal-tub Div }} \times \frac{\text { el pal-tub div }}{\text { el pal-tub div }}
$$

and seeds were obtained from 52 capsules. Plants showing whole plant mutation of pal-rec were not significantly more frequent in the cross-over classes (with respect to the flanking markers) than in the non-cross-over class el div ( 7.2 per cent as compared with $8 \cdot 1$ per cent). Indeed, it was clear from the tendency of mutants to be concentrated in clusters in a minority (13) of the capsules, with no mutants occurring in the majority (39 capsules), that at least the greater number of mutations occurred prior to meiosis. The large three-point test progeny was divided into the various phenotypically distinct classes (table 3) (El/el is not easily scorable in plants homozygous for pal-tub).

\section{TABLE 3}

Progeny classes in a three-point test for meiotic crossing-over

\begin{tabular}{|c|c|c|}
\hline Pattern of crossing-over* & Genotype & Number \\
\hline n.c.o. & el pal-rec div (including $180 \mathrm{Pal}$ mutants) & 2914 \\
\hline 1 & el pal-tub Div + & 3792 \\
\hline n.c.o. & Elpal-tub Div $\}^{\top}$ & $3 / 92$ \\
\hline 1 & El pal-rec div (including $65 \mathrm{Pal}$ mutants) & 844 \\
\hline 2 & el pal rec Div (including $14 \mathrm{Pal}$ mutants) & 254 \\
\hline 2 & El pal-tub divl & \\
\hline 1,2 & el pal-tub div $\}$ & 293 \\
\hline 1,2 & El pal-rec Div & 7 \\
\hline $\begin{array}{l}\text { * n.c.o., no cro } \\
\text { 1, crossing-o } \\
2 \text {, crossing-o }\end{array}$ & $\begin{array}{l}\text { sing-over. } \\
\text { er between } e l \text { and pal. } \\
\text { er between pal and div. }\end{array}$ & \\
\hline
\end{tabular}

Assuming that the recombinant classes El pal-tub Div and el pal-tub div were equal to the distinguishable reciprocal classes, recombination frequencies in the intervals $e l \rightarrow p a l$ and $p a l \rightarrow d i v$ are 20.83 per cent and 6.66 per cent respectively. The small number of double cross-over indicates a high degree of interference, the coefficient of coincidence being $0 \cdot 12$. The recombination intervals agree well with those given by Kuckuck (1938).

\section{(iii) Identification of hypostatic genes}

The sectors and twin-spots recorded in the several heterozygous families revealed the presence and nature of some of the hypostatic genes. Whether the uncovering of the recessive gene was due to somatic crossing-over or some other genetic cause was not always clear, particularly when a completely dominant allele was involved since no twin-spots could then occur.

(a) Incolorata/incolorata. The heterozygous flowers are medium magenta and the twin-spot illustrated in fig. 1 shows the homozygous acyanic component (inc/inc) and the darker component (Inc/Inc). Untwinned homozygous sectors are shown in fig. 4 and an unusual lobe with many aberrant 
acyanic sites in fig. 6. This spangled lobe is reminiscent of the "mutable" lobe described by Cuany, Sparrow and Pond (1958) in their irradiated heterozygous line of Antirrhinum majus which unfortunately was genetically unsuitable for the identification of any induced twin-spots.

(b) Pallida/pallida-recurrens. The twin-spot shown in fig. 2 clearly identifies the homozygous flaking pal-rec sector and the more darkly pigmented Pal/Pal component to the left.

(c) Eosinea/eosinea. Only single components (eos/eos) of any twin-spot would be identifiable: the homozygous eos tissue synthesises the pink pelargonidin anthocyanidin (fig. 5) while the homozygous or heterozygous Eos synthesises cyanidin with no quantitative difference. Unless genetically acyanic the Antirrhinum majus flowers are normally either cyanidin or pelargonidin synthesisers; no mixtures of the anthocyanidins occur. However, chromatographic analysis has shown that, as in the case illustrated here, both anthocyanidins can be synthesised in the same flower, but not in the same cells.

\section{(iv) Precursor analysis of aberrant sectors and twin-spots}

The mutant genes used in this study are all involved in the biosynthetic pathway to anthocyanidin synthesis. The niv gene blocks all flavonoid synthesis; inc blocks the flavanones; the eos locus controls the production of pelargonidin (eos/eos) or cyanidin (Eos); and pal causes the late block occurring after flavanon synthesis. The insertion of specific precursors into Antirrhinum majus with blocked pathways (Stickland and Harrison, 1974; Harrison and Stickland, 1974) has enabled anthocyanidin synthcsis to proceed. For example, the administration of dihydrokaempferol to an Antirrhinum flower blocked solely by niv/niv and/or inc/inc can synthesise cyanidin if the flower is Eos, or pelargonidin if eos/eos. The plant can add the extra hydroxyl to the $B$ ring needed for cyanidin synthesis from dihydrokaempferol $(1 \mathrm{OH})$. If the precursor given is dihydroquercetin $(2 \mathrm{OH})$ then only cyanidin can be synthesised irrespective of the eos/Eos constitution. Since the dihydroflavone naringenin cannot initiate synthesis in an inc/inc and neither dihydroquercetin nor naringenin can initiate synthesis in a flower homozygous for recessive pal alleles, the aberrant sectors produced in plants heterozygous for niv, inc, eos and pal can be analysed by precursors. Thus, an acyanic site that might be niv, pal or inc can be identified by the administration of naringenin and dihydroquercetin. If no synthesis occurs with naringenin the flower sector must have a block in synthesis aftcr the flavone stage i.e. it is either inc/inc or pal/pal; if the sector is then tested with dihydroquercetin and synthesis occurs, it must be blocked at the inc stage and not at the late pal point; similarly, if there is no synthesis following the administration of dihydroquercetin then the pal block is operating and the sector is homozygous for one of the recessive pal alleles. Although pelargonidin sectors can be analysed by chromatographic methods it is also possible to observe the extra synthesis of cyanidin in addition to the naturally occurring pelargonidin if dihydroquercetin is administered.

This technique has enabled many sectors to be related to precise genetic blocks and thus provides evidence as to which of several genes in a composite genotype is involved in the somatic aberration. 


\section{(v) Deficiencies}

Until corolla tissue culture in Antirrhinum majus allows a cytological/ genetical analysis of somatic aberrations the causes of the various mosaic types must, to some extent, remain conjectural. Amongst the heterozygous inc/Inc and pal-rec/Pal plants were several possible examples of deficiencies: either intrachromosomal deficiencies caused by deletion at the relevant loci or whole chromosome loss following non-disjunction. The heterozygous inc/Inc medium magenta coloured flowers can exhibit white or dark magenta sectors presumably by crossing-over, as described and illustrated in fig. 1; this, as in the photograph, can show as a white and dark magenta twin-spot against a medium magenta background or if the dark magenta (Inc/Inc) component fails to establish a cell lineage then as a single acyanic area. The reciprocal situation is more difficult to detect since variations in the intensity of pigmentation obscure the identification of dark magenta sites against medium magenta unless visually aided by the presence of an accompanying white component. Somatic segregants of different growth rates are unlikely to occur but if the heterozygote loses part of the Inc region or if the whole chromosome is missing then slower growth might be expected. Fig. 4 shows two flowers, one $(a)$ with a white sector, presumably homozygous inc, in which the sector is showing a normal growth pattern; the other $(b)$ has a distorted sector on the central part of the bottom lobe of the corolla with a much reduced area; this would suggest that the sector is hemizygous for inc (both synthesised cyanidin with dihydroquercetin). Similarly, in fig. 3 the heterozygous pal-rec/Pal flower has a flaking sector which could have arisen from somatic crossing-over to give a homozygous pal-rec sector; the upper companion flower also has a flaking sector but in this case a notch at the periphery of the flower indicates a slower growth rate; also, the frequency of flaking is reduced quite significantly. If only one pal-rec allele is present then the number of mutations to $P a l$ is approximately half of the homozygote. Counts on these two flower sectors agree with this view: a 9 sq. $\mathrm{mm}$ area on the normally growing sector contained 179 mutant sites while a similar area on the slower growing and probably deficient sector had 80 .

\section{(vi) Cytological analysis of aberrant plants}

If the somatic aberration affects the heterozygous genes early in the ontogeny of the flower a large sector or the whole flower can be altered; still earlier onset can affect the whole plant and this may be analysable both germinally and somatically. This occurred in two plants in the inc/Inc $\mathrm{F}_{1}$ families. Both plants were acyanic and the inference was that by crossingover or deficiency they were inc/inc, inc/inc ${ }^{-}$or inc/-. One plant was also sterile, suggesting a deficiency rather than crossing-over. Analysis of these whole plant aberrants might afford an explanation of some of the somatic aberrant sites that cannot, without an advance in tissue culture techniques, be examined cytologically. The plants were kindly examined by Mr G. E. Marks of the John Innes Institute. The sterile plant (22 per cent stainable pollen with acetocarmine) was heterozygous for a single interchange at least but the chromosomal reason for the semi-sterility (48 per cent stainable pollen) in the second plant is not yet known. 


\section{(vii) Relative size of twin-spots}

If somatic crossing-over in heterozygous Antirrhinum majus plants were the principal mechanism producing twin-spots then components of approximately the same size would be generally expected. In inc/Inc flowers any segregants involving the locus would have an acyanic and a darkly pigmented component. Measurements of the acyanic/dark magenta twin-spots (1975 data) which were conjecturally inc/inc: Inc/Inc showed 71 in which the components were of equal size; 29 in which the acyanic component was larger and 23 in which the dark magenta component was larger. These measurements indicate that the acyanic cells were not at a growth disadvantage and that the majority, if not all, the twin-spots were more likely to be the result of somatic crossing-over; acyanic components arising by non-disjunction would have been at a disadvantage in establishing a cell lineage.

\section{(viii) Twin-spots and single sites on laterals and main inflorescence}

It has been previously noticed by J. R. S. Fincham and B. J. Harrison that the developmental stage of the plant affects the frequency and type of mutation (Fincham, 1970). In particular, plants heterozygous for pal-rec/ pal-tub and pal-rec/pal-tincta show large sectors on the lateral side shoots than on the main inflorescence. Table 4 shows that this differential effect operated

\section{TABle 4}

Frequencies of single and twin-spot sites on laterals and main spike $\mathbf{F}_{1}$ plants of genotype inc:Pal/Inc:pal-rec

\begin{tabular}{|c|c|c|c|c|c|c|}
\hline & & Sin & sites & & Twi & sites \\
\hline & Sites & $\begin{array}{l}\text { Flowers } \\
\text { examined }\end{array}$ & $\begin{array}{c}\text { Frequency/ } \\
\text { Flower }\end{array}$ & Twins & $\begin{array}{l}\text { Flowers } \\
\text { examined }\end{array}$ & $\begin{array}{c}\text { Frequency/ } \\
\text { Flower }\end{array}$ \\
\hline [ain spikes & 180 & 9188 & 0.020 & 30 & 9188 & 0.003 \\
\hline Laterals & 454 & 51061 & 0.009 & 59 & 51061 & 0.001 \\
\hline
\end{tabular}

Laterals

$\mathrm{F}_{1}$ plants from crosses of inc: $P$ al $\times$ stocks not containing pal-rec (Inc:Pal or niv:Inc:Pal or Inc:pal-tincta)

\begin{tabular}{|c|c|c|c|c|c|c|}
\hline & \multicolumn{3}{|c|}{ Single sites } & \multicolumn{3}{|c|}{ Twin-spots } \\
\hline & Sites & $\begin{array}{l}\text { Flowers } \\
\text { examined }\end{array}$ & $\begin{array}{c}\text { Frequency/ } \\
\text { Flower }\end{array}$ & Twins & $\begin{array}{l}\text { Flowers } \\
\text { examined }\end{array}$ & $\begin{array}{c}\text { Frequency } \\
\text { Flower }\end{array}$ \\
\hline Main spikes & 234 & 5924 & 0.040 & 22 & 5924 & 0.004 \\
\hline Laterals & 310 & 30430 & 0.010 & 25 & 30430 & 0.001 \\
\hline
\end{tabular}

for the expression of single- and twin-spot sites. Significantly more $(\mathbf{P}<0.001)$ single and twin-spot sites occurred on the main inflorescence than on the laterals; a 3-4-fold difference was generally found. This result might arise from ageing processes within the plant or from the different environmental conditions operating at the time of development. Vig and Paddock (1970) found an increase in twin-spotting in Glycine max after cold shocks $\left(3^{\circ} \mathrm{C}\right)$ and variability in the frequency of spots according to leaf position on the plant. However, the temperature records (table 5) of the 
TABLE 5

Temperature range during experimental periods

\begin{tabular}{llc}
\multicolumn{1}{c}{1975} & $\overbrace{\begin{array}{c}\text { Range in 10-day } \\
\text { period }\end{array}}^{\text {Scan daily }}$ \\
July 4-13 & Max. 21.9 & $24 \cdot 4-18 \cdot 9$ \\
July 14-23 & Min. 13.2 & $15 \cdot 6-8 \cdot 9$ \\
& Max. 22.0 & $26 \cdot 7-18 \cdot 9$ \\
July 24-Aug. 2 & Min. 14.0 & $16 \cdot 7-12 \cdot 2$ \\
& Max. 23.4 & $29 \cdot 4-17 \cdot 8$ \\
& Min. 11.3 & $16 \cdot 7-7 \cdot 8$
\end{tabular}

three 10-day periods are sufficiently comparable not to expect any major effect of temperature on the outside plants during the scoring of the main spike and laterals. Main spikes were mostly scored during the first 10-day period; main spikes together with laterals during the middle period with some overlap into earlier and later periods, while mainly laterals were scored in the last period.

An analysis of single and twin-spot sites recorded on the same or consecutive days on laterals and main spikes is in table 6 . The number of flowers is relatively low but the difference between laterals and main inflorescence is consistent. The difference in expression of mosaics on laterals and main spike is probably due to an internal rather than an external cause.

\section{TABLE 6}

Site frequency on main inflorescence and laterals scored on same or consecutive days

\begin{tabular}{|c|c|c|c|c|}
\hline & & $\begin{array}{l}\text { Number of } \\
\text { flowers }\end{array}$ & Single sites & Twin-spots \\
\hline $\begin{array}{c}\mathrm{F}_{1} \text { pal-rec: }: \text { Inc/Pal:inc } \\
23-24 / 7 / 76\end{array}$ & $\begin{array}{l}\text { Main spike } \\
\text { Laterals }\end{array}$ & $\begin{array}{l}608 \\
960\end{array}$ & $\begin{array}{l}19(3 \cdot 1 \%) \\
21(2 \cdot 2 \%)\end{array}$ & $\begin{array}{l}1(0.2 \%) \\
1(0.1 \%)\end{array}$ \\
\hline $\begin{array}{c}\mathrm{F}_{\mathbf{1}} \text { niv: Inc eos/Niv: inc Eos } \\
17 / 7 / 75\end{array}$ & $\begin{array}{l}\text { Main spike } \\
\text { Laterals }\end{array}$ & $\begin{array}{l}673 \\
388\end{array}$ & $\begin{array}{l}64(9 \cdot 5 \%) \\
15(3.9 \%)\end{array}$ & $\begin{array}{l}9(1.3 \%) \\
1(0.3 \%)\end{array}$ \\
\hline
\end{tabular}

The effect of internal environment on the frequency of mosaic formation can be seen by comparing the two surfaces of the corolla: on the forward facing surface (as shown in fig. 6) the number is very much higher. No comparative counts were made since the reverse surface was less amenable to counting but the conclusion is unequivocal and the decreased number of mosaics on the reverse side accords with the lower number of somatic mutations of pal-rec to Pal. This effect was also noted by Vig (1974) in Nicotiana where the frequency of aberrant sites was much greater on the upper surface of the leaf than on the lower.

It is perhaps relevant in the context of internal environment effects to record the difference in mutability of the pal-rec allele in the male and female germ line (Harrison, 1967). The conclusion was based on 4861 plants of pal-iub $\times$ pal-rec and pal-tincta $\times$ pal-rec (from 79 crosses) and compared with 2722 plants of a reciprocal set (from 48 crosses). Although there was some scatter in the percentage values of mutations within each class, the standard error of the mean percentages and a $\chi^{2}$ test showed a difference 
in mutability dependent on whether the mutable gene was in the pollen or ovules (table 7$)$. $(\mathrm{P}<0.001$ if analysis is based on the minimum number of distinct mutations i.e. using the number of capsules in which one or more mutants occurred rather than the number of mutants; a capsule could give rise to a number of mutant plants but all could be the result of a single early mutation.)

\section{TABLE 7}

Frequencies of gametic mutations of pal-rec in male and female germ lines

$\left.\begin{array}{l}\left.\begin{array}{l}\text { Female } \\ \text { pal-rec } \times \text { pale } \\ \text { pal-rec } \times \text { pal-tubta } \\ \text { pal-tincta } \times \text { pal-rec } \\ \text { pal-tub } \times \text { pal-rec }\end{array}\right\}\end{array}\right\} \quad \begin{gathered}\text { Mean } \% \text { of mutation } \\ 12.6 \pm 3.2 \text { (S.E.M.) } \\ 31 \cdot 1 \pm 7 \cdot 7 \text { (S.E.M.) }\end{gathered}$

(a) Site counts on homozygous lines. Two inbred lines were assessed for aberrant single sites and twin-spots. The first was a full-red line $(\mathrm{Pal})$ that originated from a highly inbred homozygous pal-rec; the second was homozygous pal-carnea (a pale magenta). Both lines were inbred for the major genes used in the current work, but some residual heterozygosity is possible for unknown genes affecting pigmentation and these would differ between the two lines. Barrow, Ghaudhari and Dunford (1973) concluded that, in their " homozygous" cotton, heterozygous sectors derived from homozygous cells. Some residual heterozygosity with no apparent phenotypic effect may have existed. They additionally considered it possible that a pseudo-allelic condition with crossing-over within the gene between two minute mutations could explain the observed segregation. A cross-over within a pericentric inversion could also give duplication and deficiencies for two colour genes expressable as twin-spots. Such possibilities add to the complexity in interpreting the aberrant areas solely in terms of known heterozygous genes in purposely made $F_{1}$ s. Single sites in homozygous lines arising from point mutations of unknown genes would be expected to occur at approximately the same frequency as in purposely made heterozygous lines. It can thus be considered that a background level of aberrations will be common to both homozygous lines and heterozygotes and the counts recorded in table 8

TABLE 8

Aberrant site frequency in three homozygous lines

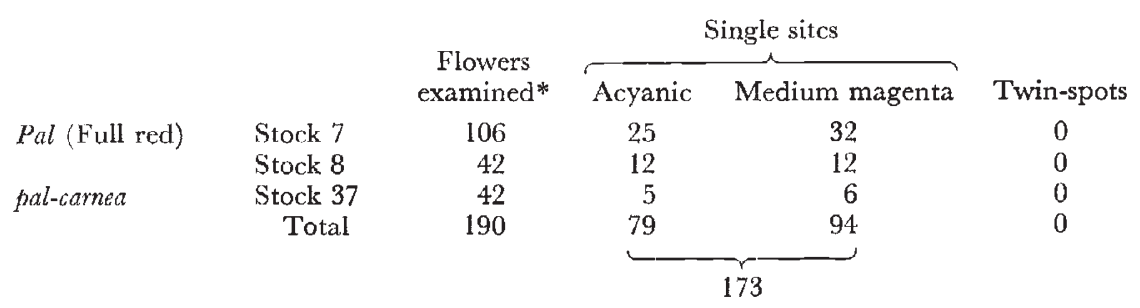

* Whole flower counted; for comparison with single lobe counts the whole flower count is divided by 4 .

173 single sites $/ 190 \times 4=$ frequency of 0.23 single sites per lobe compared with 0.96 (inc/Inc) in table $9 ; 1.47$ (Eos: Niv/eos:niv) in table 10;1.69 (Niv:Pal:Sulf/niv:pal-tub:sulf) in table 11 . 
provide an estimate for the background level. It is significant that no twinspots were recorded and that the mean estimate of 0.23 single sites per lobe is approximately $1 / 7$ of the frequency recorded in the $F_{1} s$ (table 9 ). The comparison should be made with the untreated controls in the caffeine data (tables 9, 10 and 11) since these plants had similar growing conditions to those for the homozygotes and were all counted microscopically.

\section{TABLE 9}

Effect of caffeine on the incidence of single and twin-spot sites

\section{Genotype \\ Incolorata/incolorata}

Flowers examined

UNTREATED

70 (3 plants)

Mean number of aberrant sitcs per lobe

\section{Treated}

$0 \cdot 25 \%$ CAFFEINE $(24 \mathrm{hrs})$ 26 (3 plants*:

D82 $3,4, R 8$

Mean number of aberrant sites per lobe

Fold increase over untreated

\section{Treated \\ $0.5 \%$ CAFFEINE ( $24 \mathrm{hrs}$ ) 29 (4 plants* : \\ D82 1, 4, R11, R14)}

Mean number of aberrant sites per lobe

Fold increase over untreated
Twin-spots

$\overbrace{\text { Acyanic Pale magenta }}^{\text {Single sites }} \overbrace{\begin{array}{c}\text { Acyanic/ } \\ \text { Dark magenta }\end{array} \text { Acyanic/Pale Pale/Dark }}^{\text {Twin-spots }}$

$0.96 \quad 0.03$

$\underbrace{123}_{749}$
$\begin{gathered}626 \\ 28 \cdot 8 \\ \times 30\end{gathered}$

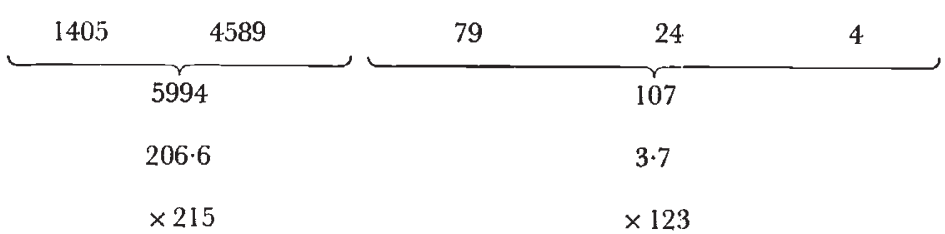

* Only those flowers from affected part of inflorescence recorded.

$\dagger$ Only upper left-hand lobes of corollas counted.

\section{(ix) Caffeine treatment}

The effect of caffeine on higher plants in increasing the frequency of somatic crossing-over and point mutation has been demonstrated in Glycine max by Vig (1975) and for chromatid exchanges in Allium by Kihlman et al. (1971). It appears to have little influence on the frequency of other genetic aberrations resulting from other causes. If caffeine increases the rate of crossing-over, treated heterozygotes for suitable genes should show an 
increase in the number of twin-spots; sites resulting from point mutations will also increase but these will be single sites.

Table 9 shows that untreated heterozygotes of incolorata/Incolorata had a mean of 0.96 single sites per flower lobe and the lower figure of 0.03 twinspots per lobe. (Only one lobe, the upper left facing the flower, was counted in detail using a binocular microscope.) This estimate would be approximately one-quarter of the abcrrations on the whole front surface of the flower (see Methods) excluding the corolla tube.

TABLE 10

Effect of caffeine on the incidence of single and twin-spot sites

$\overbrace{\text { Acyanic Pale magenta }}^{\begin{array}{c}\text { Gosinea }: \text { Nivea/eosinea: nivea } \\ \text { Single sites }\end{array}} \overbrace{\begin{array}{c}\text { Acyanic/ } \\ \text { Dark magenta }\end{array} \text { Acyanic/Pale Pale/Dark }}^{\text {Twin-spots }}$

\section{UNTREATED}

121 (8 plants)

Mean number of sites per lobet

$\underbrace{11}_{\substack{178 \\ 1.47}} \underbrace{1}_{\begin{array}{c}2 \\ 2 \\ 0.02\end{array}}$

TREATED

$0 \cdot 25 \%$ CAFFeine ( $24 \mathrm{hrs}$ ) $21(3)^{*}$

Mean number of sites per lobe

Fold increase over untreated

$\underbrace{105}_{\begin{array}{c}1160 \\ 55.24\end{array}} \underbrace{1055}_{\substack{22 \\ \times 37.58}} \begin{gathered}1.05 \\ \times 52.5\end{gathered}$

TREATED

$0.5 \%$ CAFFEINE $(24 \mathrm{hrs})$

$10(3)^{*}$

Mean number of sites per lobe

Fold increase over untreated

$\underbrace{672}_{578} \underbrace{6_{070}^{0}}_{0}$

$57 \cdot 8$

$$
\times 39 \cdot 32
$$

$* \dagger$ See Table 9.

The acyanic single sites could result from deficiencies or point mutation at the Inc locus or from the homozygous recessive component of a twin-spot. The pale magenta single sites could arise from unknown heterozygous genes affecting pigmentation in the purposely constituted inc/Inc genotype. Pale magenta areas werc conspicuously present in much of the material examined and some twin-spots of pale magenta with an acyanic or dark magenta component were recorded. The origin of these aberrants can only be conjectured but whatever the cause it is increased by caffeine treatment and thus could be either the consequence of point mutation or crossing-over.

The sensitivity of the young buds to caffeine varied from no effect, 
FIG, 1.- Twin-spot comprising an acyanic inc/inc and dark magenta Inc/Inc components on the medium magenta background of the heterozygous inc/Inc flower.

Fig. 2.- Twin-spot of a flaking pal-rec/pal-rec component with the dark magenta Pal/Pal on medium-dark magenta background of the heterozygous pal-rec/Pal flower.

\section{Plate II}

F1G. 3.-Upper. Sector on pal-rec/Pal flower of 80 mutant sites $/ 9 \mathrm{sq} \mathrm{mm}$ and peripherally indented; the low flaking and reduced growth indicates an absence (following nondisjunction or a deficiency) of the Pal chromosome or region which allowed the expression of the single unstable pal-rec allele.

Lower. Normal growth of a pal-rec/pal-rec sector with parental flaking frequency (179 mutant sites/9 sq mm) caused by somatic crossing-over in the pal-rec/Pal flower.

Fig. 4.-(a) Left. Acyanic sector of inc/inc (synthesised cyanidin with dihydroquercetin) with normal growth on inc/Inc flower.

(b) Right. Acyanic central lower lobe of reduced growth (synthesised cyanidin with dihydroquercetin); probably due to deficiency $\left(\right.$ inc/inc ${ }^{-}$) or chromosomal loss (inc/-) on an inc/Inc flower.

\section{Plate III}

FIG. 5.--Large sector of eos/eos (pelargonidin pigment) on an eos/Eos (cyanidin pigment) flower.

FIG. 6.--Localised multiplicity of acyanic sites $(+2$ twin-spots) on one lobe of an inc Eos:Pal/Inc eos:pal-rec flower.

Plate IV

FIG. 7.- Acyanic sites and twin-spots on an inc/Inc (D82 $\left.{ }^{\mathrm{R} 11}\right)$ flower after 24-hour treatment at bud stage with 0.5 per cent caffeine.

Fig. 8.- Three twin-spots $($ inc/inc $+\operatorname{Inc} / \operatorname{Inc}$ ) on part of a corolla lobe from a caffeine treated $(0 \cdot 25$ per cent) inc/Inc inflorescence (D824).

FIG. 9. - Inflorescence of inc/Inc plant (D82 ${ }^{\text {R11 }}$ ) treated with 0.5 per cent caffeine. Stunted flowers followed by a sequence with numerous acyanic sites and twin-spots.

\section{Plate V}

FIg. 10 

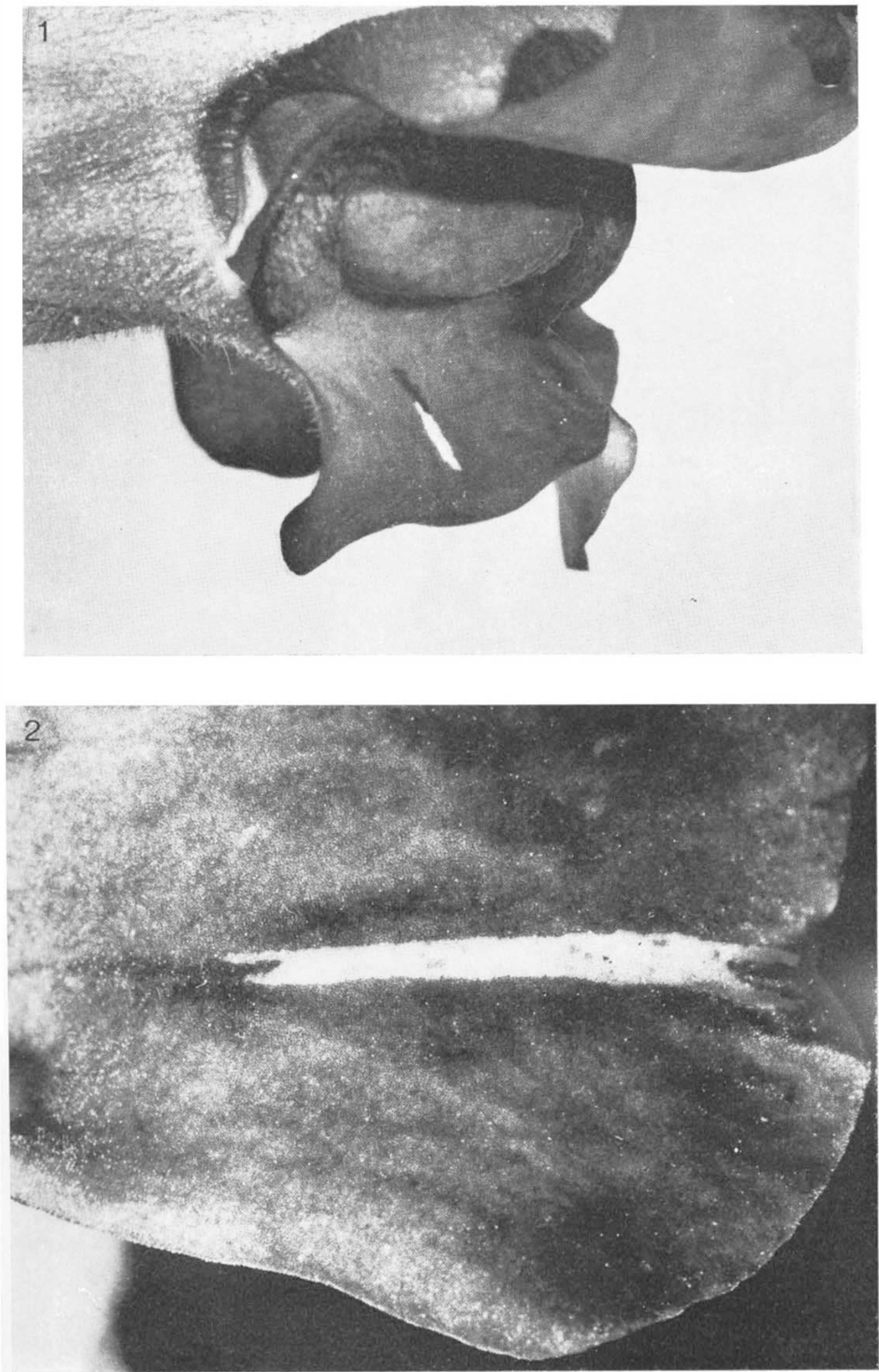
Plale II

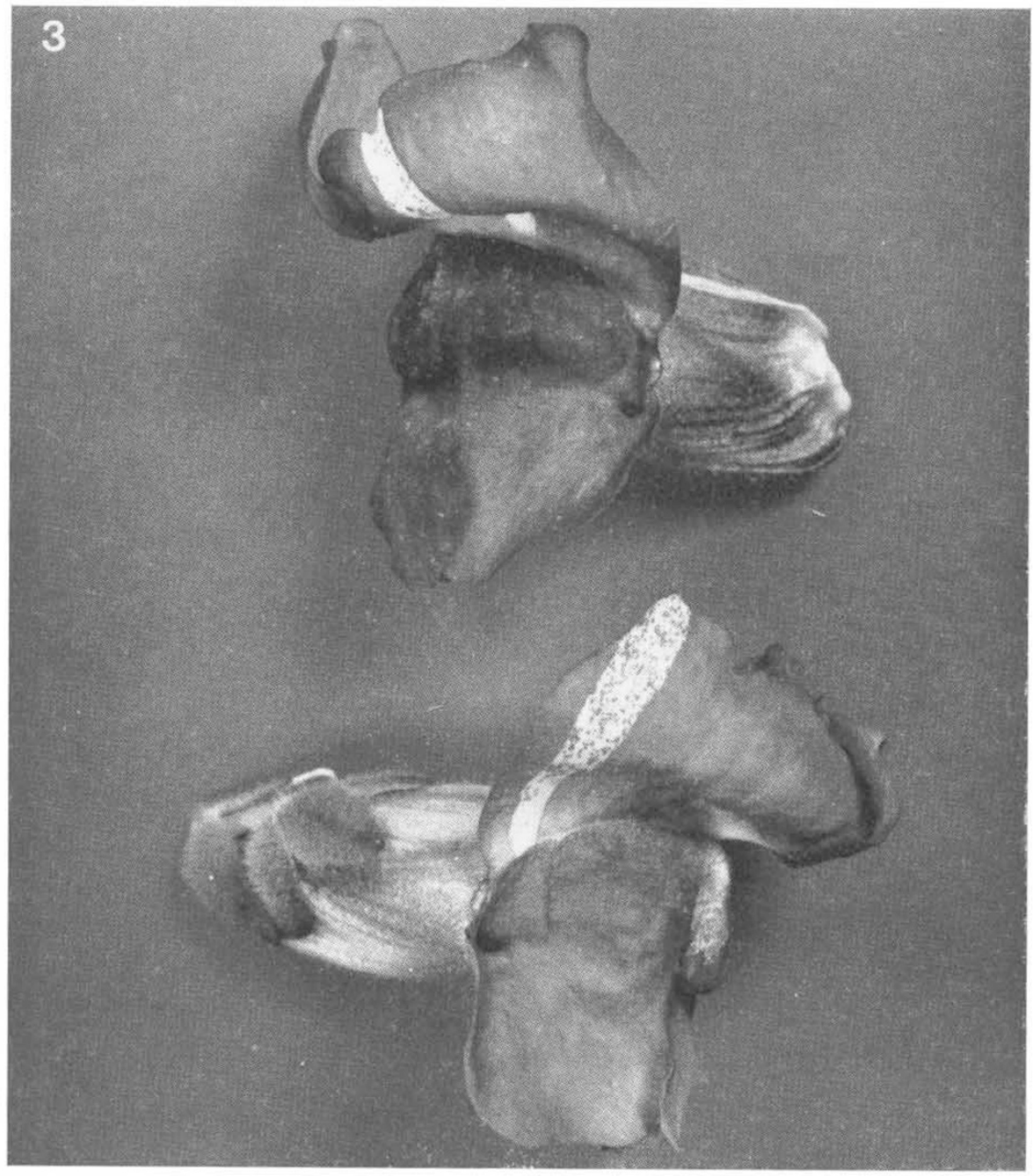

4
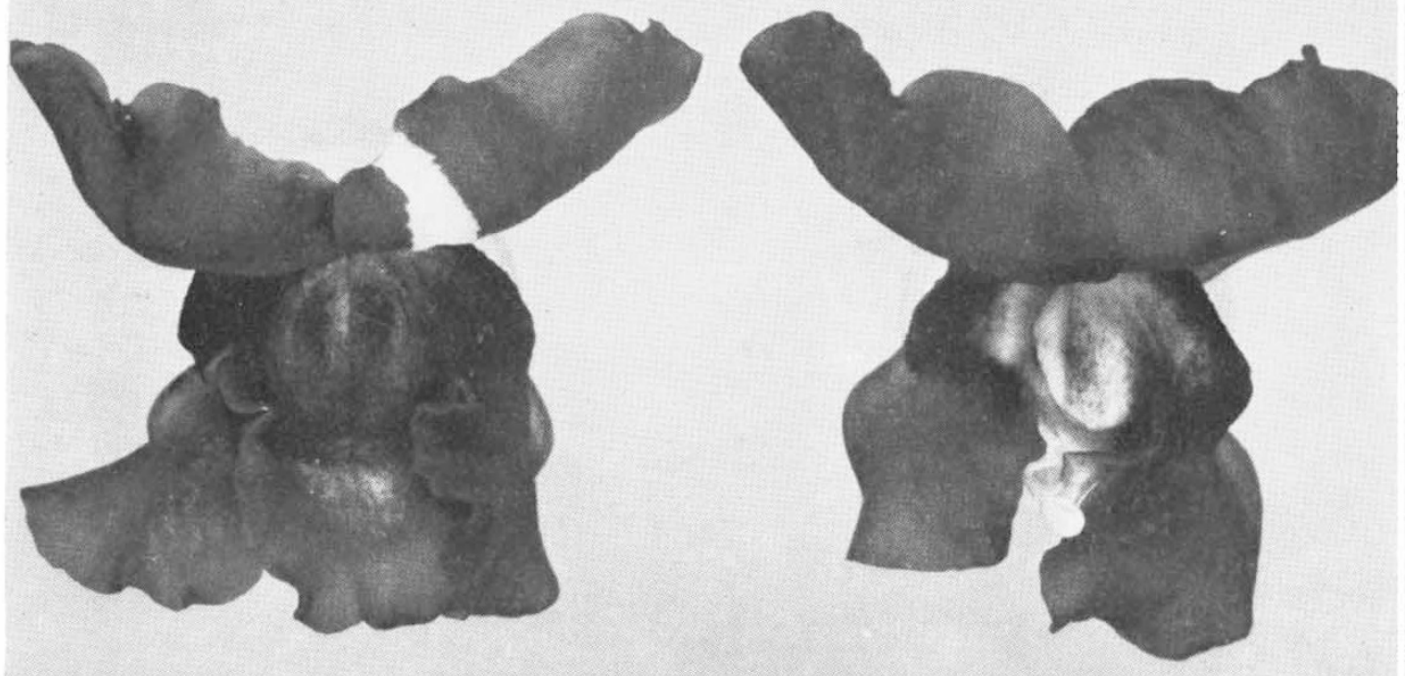
Plate III
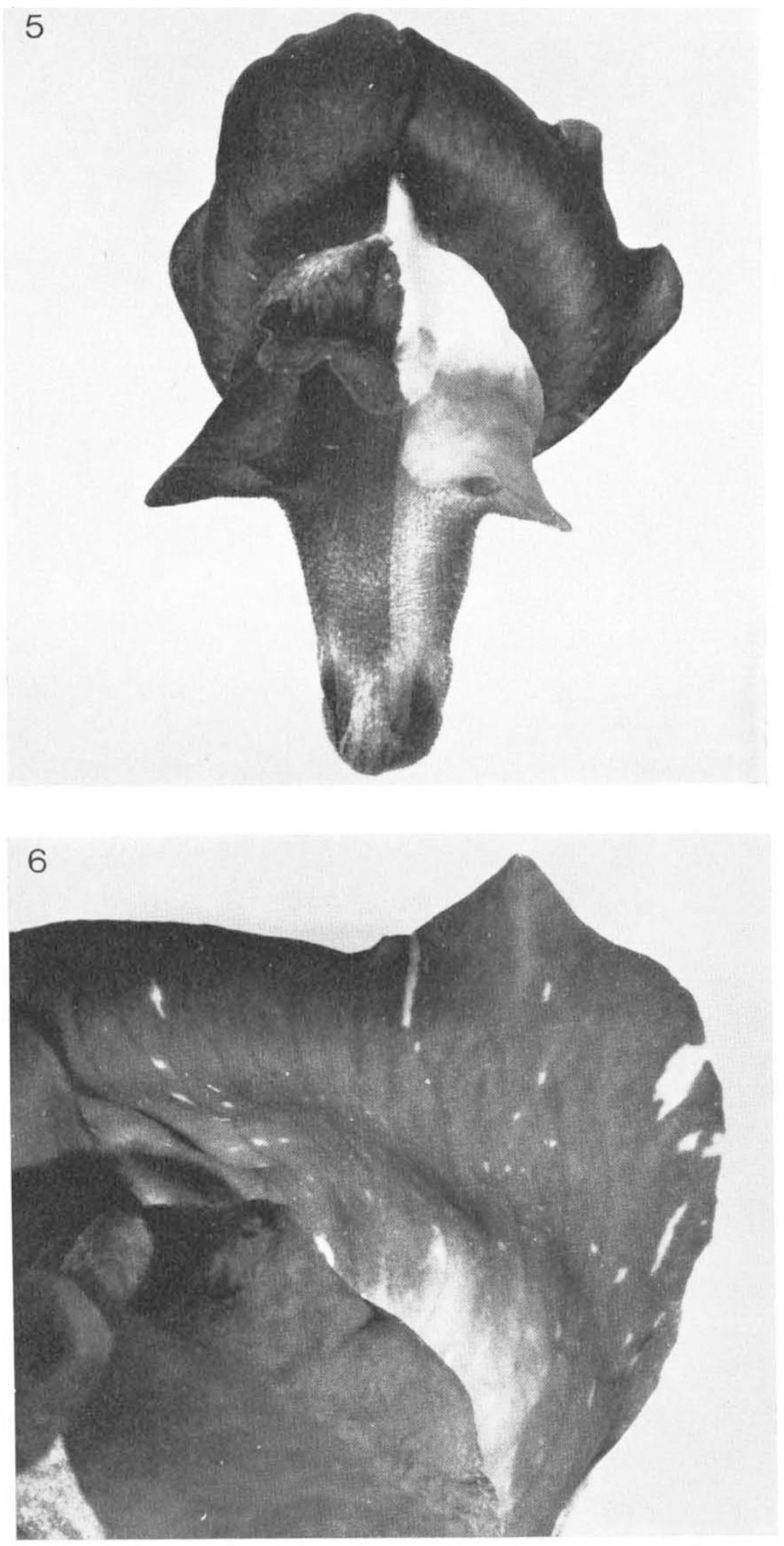
Plate IV
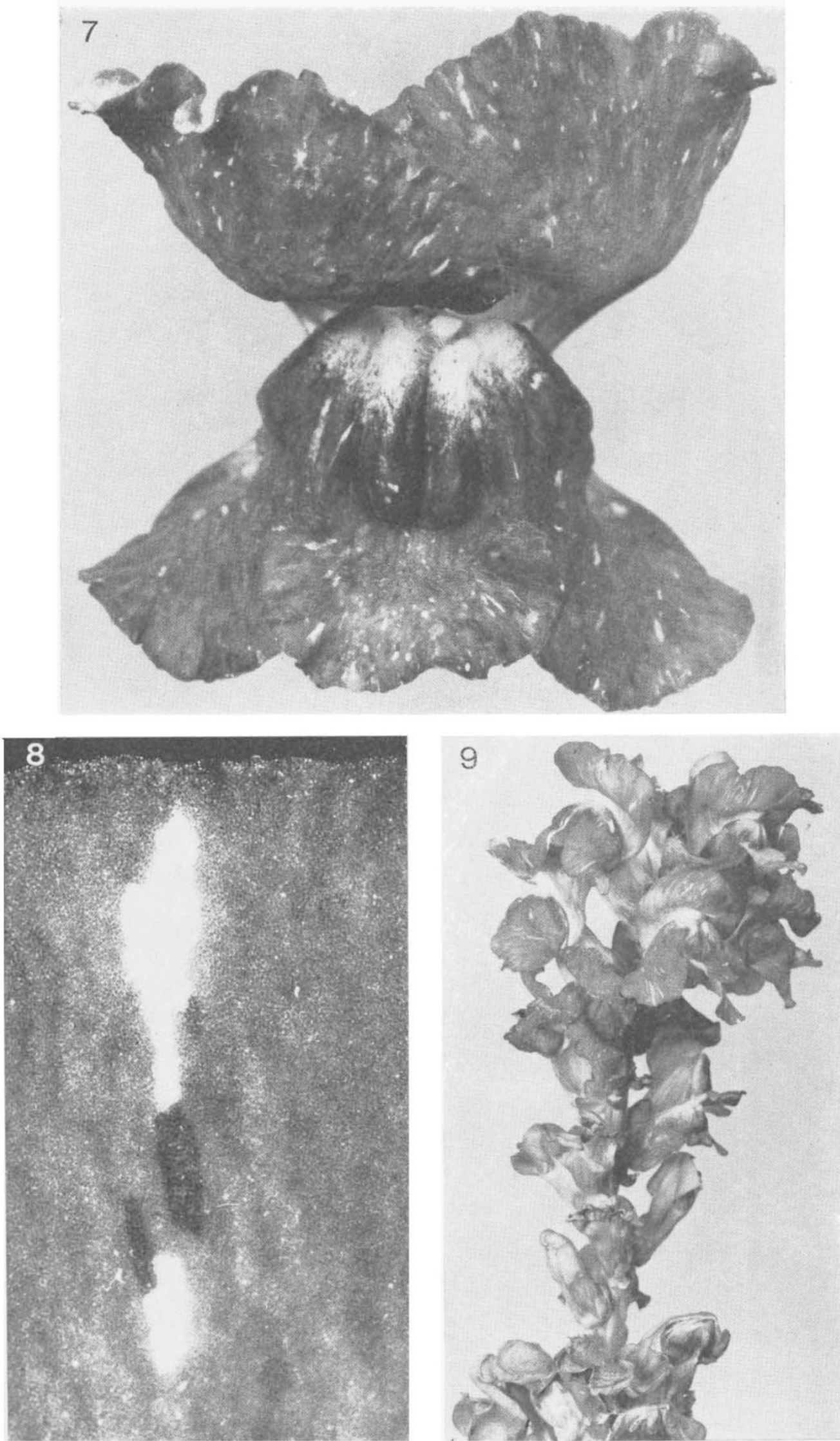
Plate $V$

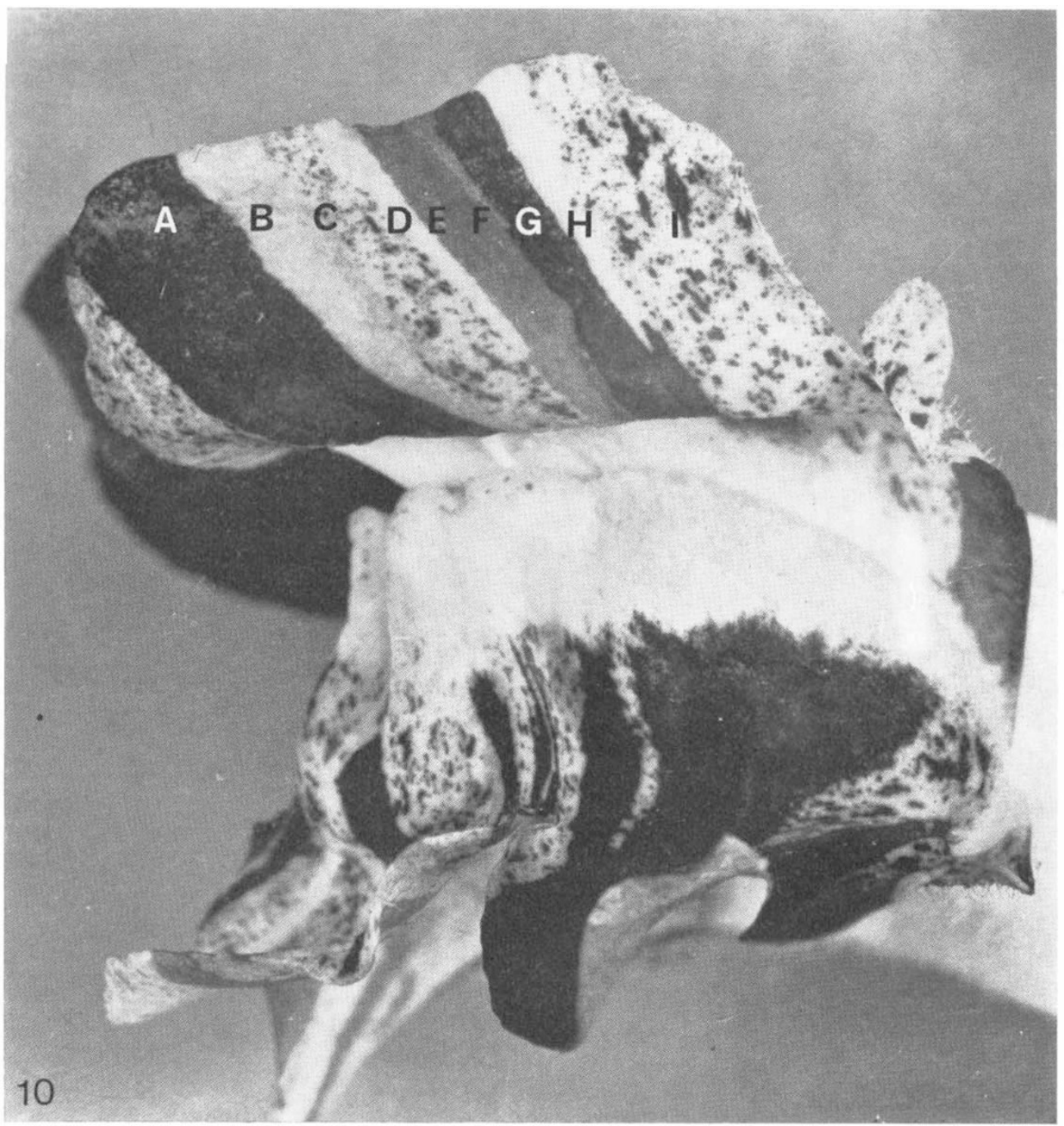

FIG. 10.-Probable constitution of sectors on a pal/rec/pal-rec flower:
A PallPal (or any other pal allele).
B pal-carnea/pal-carnea (or pal-tincta or pal-tub).
C pal-rec/pal-rec.
D pal-tincta/pal-tincta (or pal-tub) or pal-tub/pal-tub.
E pal-rubra/pal-rubra (or pal-carnea, tincta or $t u b$ ).
F pal-carnea/pal-carnea (or pal-tincta or pal-tub).
G Pal/Pal (or any other pal allele).
H pal-tincta/pal-fincta (or pal-tub).
I pal-rec/pal-rec. 
through variable frequencies of increased aberrant sites to gross abortion. Fig. 9 shows an inflorescence of $i n c / I n c 42$ days after a 0.5 per cent treatment; the central part has aborted flowers while the top has a large number of acyanic and pale magenta sites together with many twin-spots. A close-up of a flower on the same inflorescence but photographed 13 days earlier (fig. 7) exhibits so many aberrant sites that it resembles the effect of an unstable gene.

TABLe 11

Effect of caffeine on the incidence of single and twin-spot sites Genotype

Nivea:Pallida: Sulfurea/nivea : pallida-tubocolorata: sulfurea

Flowers examined

\begin{tabular}{|c|c|c|c|c|c|}
\hline \multicolumn{2}{|c|}{ Single sites } & \multicolumn{4}{|c|}{ Twin-spots } \\
\hline Acyanic & $\begin{array}{c}\text { Pale } \\
\text { magenta }\end{array}$ & $\begin{array}{c}\text { Acyanic/ } \\
\text { Pale magenta }\end{array}$ & $\begin{array}{c}\text { Acyanic/ } \\
\text { Dark }\end{array}$ & $\begin{array}{l}\text { Pale/ } \\
\text { Dark }\end{array}$ & $\begin{array}{c}\text { Pale/ } \\
\text { Medium }\end{array}$ \\
\hline 28 & 173 & 0 & 0 & 2 & 0 \\
\hline \multicolumn{2}{|c|}{201} & \multicolumn{4}{|c|}{2} \\
\hline \multicolumn{2}{|c|}{1.69} & \multicolumn{4}{|c|}{0.02} \\
\hline
\end{tabular}

Treated

$0 \cdot 25 \%$ GAFFEINE (24 hrs) $27(4)^{*}$

Mean number of sites per lobe

Fold increase over untreated

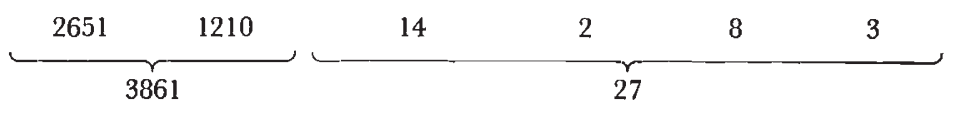

$\begin{array}{lll}143.00 & 1.04\end{array}$

$\times 85 \quad \times 52$

Treated

$0 \cdot 5 \%$ CAFFEINE $(24 \mathrm{hrs})$

$14(2)^{*}$

Mean number of sites per lobe

Fold increase over untreated

\begin{tabular}{|c|c|c|c|c|c|}
\hline 624 & 1890 & 0 & 0 & 11 & 0 \\
\hline & \\
\hline
\end{tabular}

$172 \cdot 43$

$0 \cdot 79$

$\times 102$

$\times 40$

$* \dagger$ See Table 9.

An assessment of the size of the various types of site on one lobe of the flower in fig. 7 and an approximate count on the frequency of site types, gave the following results:

20 pale magenta largest site 210 cells

53 acyanic largest site 360 cells

5 twin-spots largest site 350 cells (total for both components)

Approximately 250,000 cells comprise the whole of the upper surface of the upper lobe of this particular flower. About 10 cell generations appear to have occurred following treatment to the sensitive primordia, which gives a maximum site size of 512 cells; the smaller sizes would increase in frequency 
so long as the treatment or its effect continued during flower development.

The increase in twin-spots following caffeine treatment is exemplified in fig. 8 in which these are three twin-spots involving inc-Inc on part of one lobe.

Since the main effect of caffeine is usually restricted to a cluster of flowers on the inflorescence, representing those at the sensitive stage of

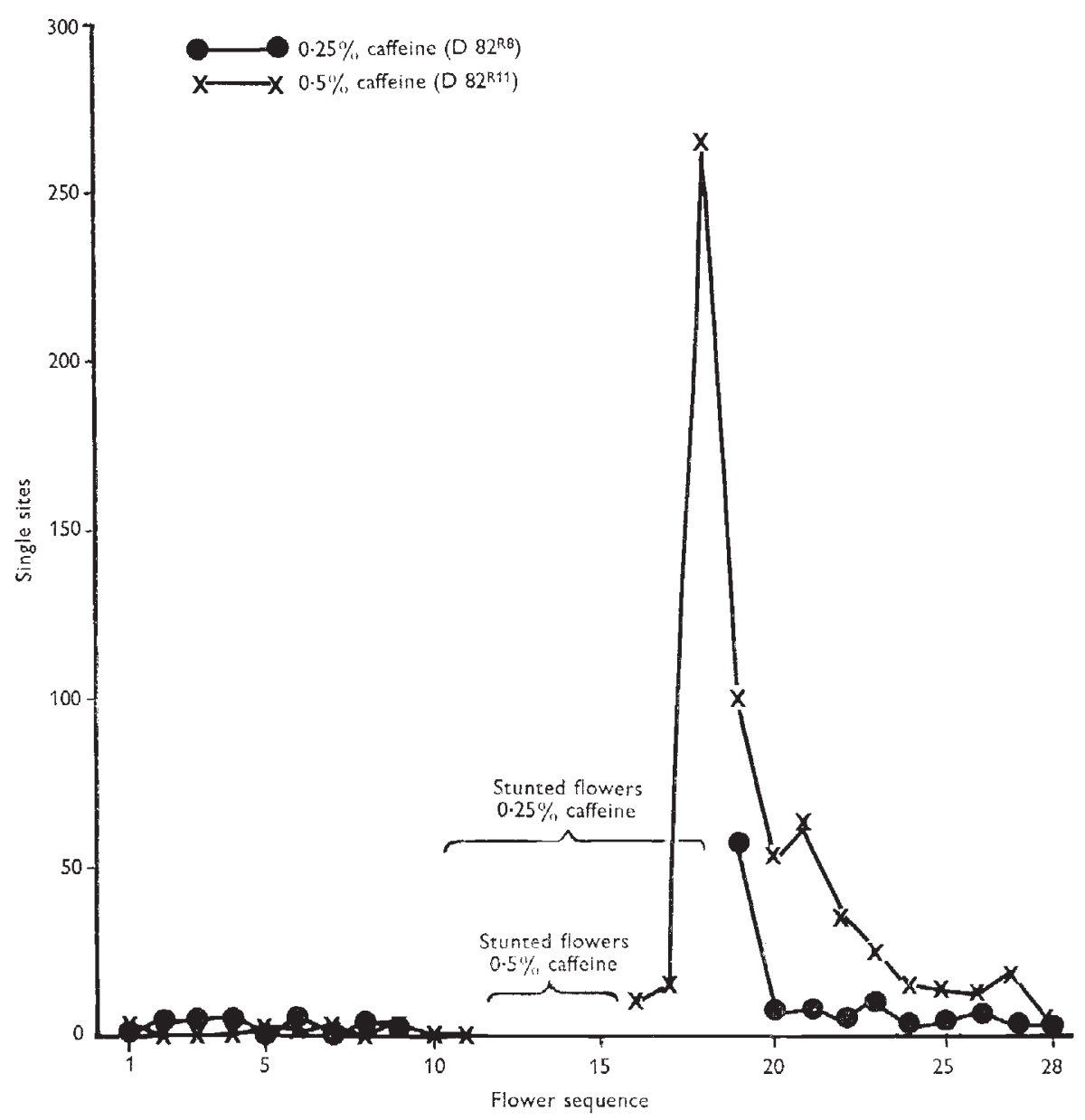

FIG. 11.-Frequency of single sites on a sequence of flowers on inflorescences of inc/Inc treated with $0.25\left(\mathrm{D} 82^{\mathrm{R} 8}\right)$ and 0.5 per cent caffeine (D82 ${ }^{\mathrm{MI}}$ ). The effcct of the 24-hour caffeine treatment begins in these particular inflorescences with a sequence of stunted flowers.

development at the time of treatment, only these flowers were sclected for recording and comparison with the untreated controls. From table 9 and figs. 11 and 12 the 0.25 per cent caffeine effected a 30 -fold increase in single sites and twin-spots while the 0.5 per cent treatment gave a $100-200$-fold increase. The effect of caffeine is unequivocal.

The data in table 10 are less informative than those in table 9. The effect of the 0.5 per cent caffeine was to produce many aborted flowers and 
the frequency of single sites indicates that the highly sensitive stage of development was not chosen. The 0.25 per cent treatment yielded a comparable increase in single sites and twin-spots to that achieved in the inc/Inc material (table 9). The niv gene suffers the disadvantage, in comparison with inc, of giving a less clear difference in pigment intensity between the heterozygous and homozygous dominant. The precise control of pigmentation by the niv gene is possibly affected by localised breakage or breakage within the gene complex. The previous work on niv and niv-rec (Harrison and Carpenter, 1973) showed a flushing phenomenon for this gene that may be

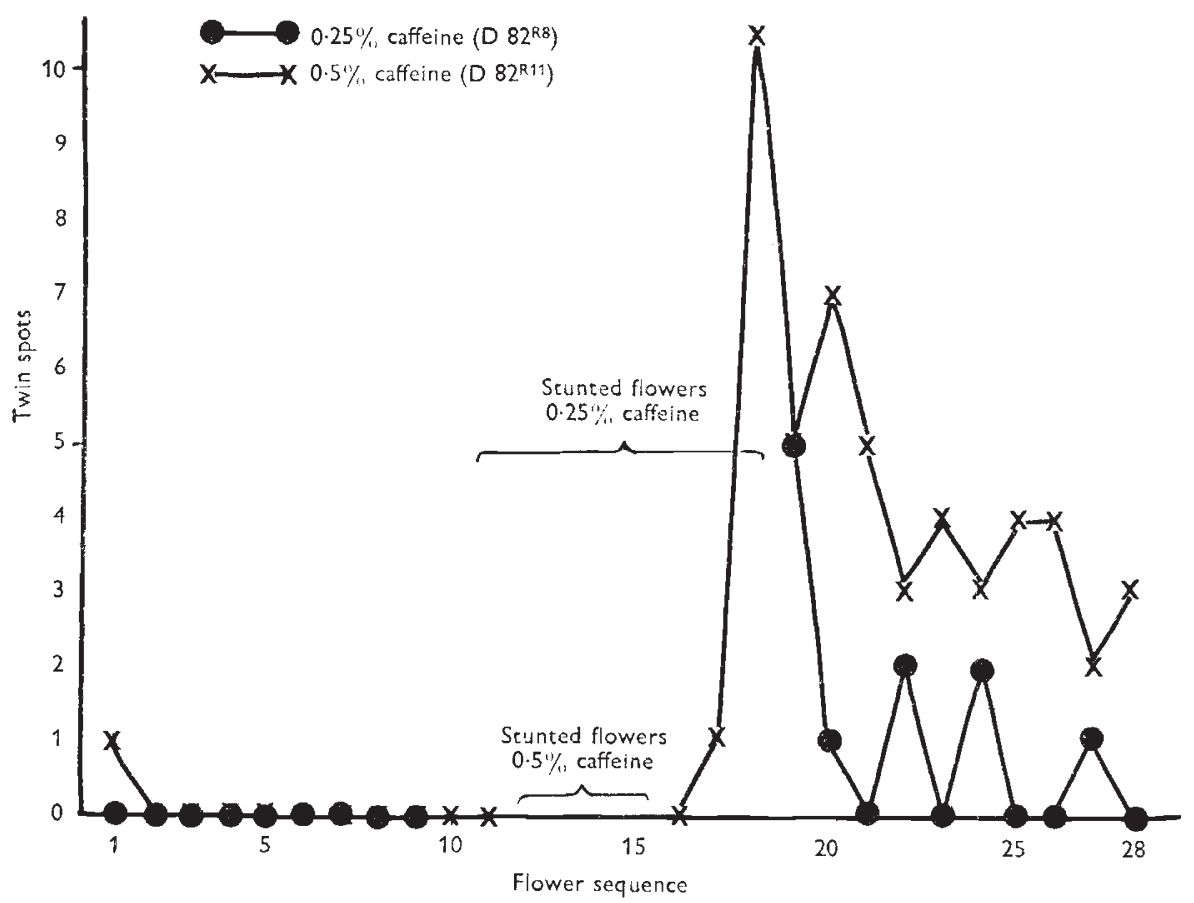

FIG. 12.-Frequency of twin-spots on a sequence of flowers on inflorescences of inc/Inc treated with $0.25\left(\mathrm{D} 82^{\mathrm{R} 8}\right)$ and 0.5 per cent caffeine $\left(\mathrm{D} 82^{\mathrm{R} 11}\right)$. The effect of caffeine in these inflorescences begins with a sequence of stunted flowers.

related to a paramutable condition. A large putative sector of niv/niv involving half an inflorescence arising in heterozygous niv/Niv was tested with the precursors naringenin and dihydroquercetin and the ensuing synthesis of anthocyanidin indicated the sector to be niv/niv but there was a slight flush of pigment present which was not expressed in the acyanic parent. If the control of niv is easily affected by localised breakage then some of the pale/dark twin-spots and pale sites may be related to this type of disturbance. The increase in the single and twin-spot sites following 0.25 per cent caffeine treatment was similar to that in the inc/Inc plants (table 9). The closeness in the absolute frequencies could indicate that niv and the unlinked inc have similar distances from their centromeres. 
No twin-spots involving eos would be seen since Eos is completely dominant and sectors of homozygous eos, which would synthesise pink pelargonidin instead of the cyanidin in the remainder of the corolla, would if small, appear as pale magenta. However, since pale magenta sites of unknown origin occur in homozygous Eos flowers it is clearly unreliable to attribute pale magenta sites to crossing-over involving the eos gene unless the sector is sufficiently large to allow a chromatographic analysis: this has been possible and is illustrated in fig. 5 in which there is the unusual situation of a flower synthesising both cyanidin (Eos/eos) and pelargonidin (eos/eos).

The effect of caffeine on the $\mathcal{N i v}:$ Pal : Sulfurea (Sulf)/niv : pal-tub : sulf heterozygote (tablc 11) is again clear but this genotype has the disadvantage of lacking distinctive components for the niv combinations. No sectors for yellow (sulf/sulf) were identified; these would be seen as a mixture of yellow aurone and magenta cyanidin and would probably be recognisible only if the sectors were large. Some of the larger acyanic sites were tested with dihydroquercctin; those that synthesised cyanidin were recorded as niv/niv and those that failed as pal-tub/pal-tub.

\section{(x) Non-recurrens sectors in homozygous pallida-rccurrens}

The unstable pal-rec allele when associated with homozygous recessive stabiliser (Harrison and Fincham, 1968) readily mutates somatically (and germinally) to the dominant fully pigmented $\mathrm{Pal}$ and less frequently to other members of the allelic series (Fincham and Harrison, 1967). If somatic mutations of pal-rec to alleles such as tincta (usually acyanic, sometimes tinged) or carnea (pale magenta flowers) occur early in the development of the corolla then, by somatic crossing-over, homozygous acyanic or palely pigmented sectors free from flaking should be identifiable at a frequency different from that expected from coincident mutations of both rec alleles. The somatic segregant pal-rec/pal-rec component re-formed from pal-rec " new pal mutant allele", will be indistinguishable from the normal flaking background. A preliminary survey of these types of non-flaking sectors in homozygous pal-rec has indicated the frequency to be higher than expected from independent mutation of both alleles. It must be recognised however, that since the pal-rec allele can be considered unusual in its high mutability it could be additionally aberrant in losing the unstable nature (Sastry, 1976) of one allele while the other mutated to another stable allelc, thus simulating a homozygous sector; two dissimilar alleles arising from the two pal-rec alleles could also simulatc a homozygous sector. The partial inactivation of pal-rec alleles described below would not easily account for the homozygous non-rec sectors since the low level of flaking would still be observable even against the pigmented backgrounds of carnea or rubra.

Variations in the frequency of somatic mutation of pal-rec are common and these vary from sectors to whole flowers, shoots or whole plants showing low mutability. This could be attributed to: $(a)$ mutations involving the stabiliser control; $(b)$ one or both alleles mutating to a stable acyanic form; (c) segregation of genes affecting instability; or $(d)$ a change of pal-rec (high $\mu$ ) to pal-reclow (Sastry, 1976) but so low as to be unrecognisable as a flaking sector. A survey of 1065 plants of pal-rec/pal-rec (normally of high mutability) were grown outside during the hot summer of 1976. The 
scoring for the frequencies of somatic mutations was on fully mature plants whose main spikes were still flowering as well as on the many laterals. 258 (24.2 per cent) plants were mutating throughout the entire plant at a high rate (mean of 2360 mutant sites per lobe); 707 (66.3 per cent) plants had mixtures of high, medium and low sectors and laterals; 15 ( 1.5 per cent) were wholly medium in flaking intensity (mean of 525 mutant sites/lobe; and 85 ( 8.0 per cent) plants were either entirely low (mean of 141 sites/lobe) or a mixture of low and medium frequencies. These massive somatic changes in mutability in populations of pal-rec/pal-rec have been seen on a previous occasion but usually the stock maintains its high flaking; the effect is only somatic, no germinal changes having been recorded. Although temperature is inversely correlated with flaking frequency (Harrison and Fincham, 1964) several other similar lines of pal-rec grown under the same conditions did not lose their high mutability and 24 per cent of the plants in the affected family maintained their normal flaking frequency. Somatic crossing-over is an unsatisfactory explanation for this phenomenon but it must be considered a possibility in some instances of sectoring for different flaking intensity, particularly when the line is heterozygous for stabiliser.

In this survey sectors occurred to alleles other than $\mathrm{Pal}$ and these were usually flaking at a frequency expected from the remaining single pal-rec allele: occasionally the flaking on a carnea type sector was low but recognisably present. A change of pal-rec $(\mathrm{H} \mu)$ to pal-reclow in one allele and a mutation to a stable allele in the other does not readily explain the occurrence of the " homozygous" type sectors which were entirely free from flaking. An array of contiguous separate mutational events resulting in non-rec sectors in a pal-rec/pal-rec flower is shown in fig. 10; in some lines recently established this behaviour is particularly common and may be the result of a Dissociator type mechanism acting somatically and instigating increased chromosome breakage and reunion (McClintock, 1951). In this particular flower there are mutations of pal-rec/pal-rec to Pal, rubra, carnea, malacea (not shown in the figure) and tincta types that on visual assessment could all be homozygous. Except for the epistatic full red Pal sector which could be heterozygous pal-rec all the remainder lack both the normal high flaking pal-rec alleles.

The occurrence of such putatively homozygous non-rec sectors presents obvious problems in interpretation. If, for example, one allele mutated to stable tincta early in the development of the inflorescence then any subsequent mutation of the remaining rec allele would appear as an unflaking sector that would simulate a homozygous sector for any several alleles. However, this does not seem likely since the flaking frequency of the rec sectors is commensurate with two rec alleles mutating. Thus, the two rec alleles appear to have mutated simultaneously to new stable alleles probably of the same type. If the mutation of one allele triggers the other then it is a mechanism that occurs relatively frequently, more than would be expected by chance, and the occurrence is more frequent in some lines. In the present context of somatic crossing-over, if one allele mutates to a stable form and is ther followed by chromosome breakage and subsequent crossing-over to give a homozygous sector it will be accompanied by its companion homozygous component that is the same as the general background and be unrecognisable. If this occurs then it does so frequently and we have already seen that mutations of pal-rec to $\mathrm{Pal}$ are not associated with either germinal or somatic crossing-over within the $e l$ to div region of the pal chromosome. 
Clearly, further investigation is needed before this peculiar behaviour is satisfactorily explained but the sectoring could be the result of a triggering mechanism of great interest or an additional manifestation of somatic crossing-over.

\section{Discussion}

The examples of somatic crossing-over in higher plants vary in their degrees of conviction and the present data add one more plausible example. The occurrence of twin-spots of the precise type expected on flowers heterozygous for known genes could be additionally tested by administering anthocyanidin precursors The synthesis or non-synthesis of pigment following imbibition of defincd precursors in the acyanic component enabled the position of the block in the biosynthetic pathway to be identified. If the position of the block identified by precursor treatment agreed with the expected block arising from homozygosity of one of the included genes in the heterozygote then the genetic nature of the component could be assumed with greater certainty even if the mechanism by which it arose is still obscure. However, many possible mechanisms can be immediately eliminated; equal growth of both components makes non-disjunction an unlikely mechanism in the majority of the twin-spots recorded. Carlson (1974) cultured the components of 12 twin-spots in the leaves of Nicotiana tabacum and concluded that 11 were the result of mitotic crossing-over and one, possibly induced by the colchicine treatment, to non-disjunction. The increase in twin-spots following caffeine treatment accords with thc work of Vig on Glycine max which showed an increase in point mutations and somatic crossing-over. Caffeine has been shown to increase the frequency of point mutations and crossing-over in plants but no other major type of aberrant mechanism consequent upon treatment has been identified although potentiating effects have been observed with chemical mutagens and ionising radiations. It is also significant that caffeine potentiation has been recorded mainly in plant and rodent cells which lack or only have inefficient excision repair mechanisms (Kihlman, 1974).

The mechanism by which caffeine (an inhibitor of oxidative phosphorylation) affects the frequency of somatic crossing-over is still conjectural. Methylated oxypurines perhaps induce fragmentation of the replicating chromosomes through an alteration in the permeability of the inner membrane of the nuclear envelope (Weber, 1968; Mizuno et al., 1971) and Doman and Rauth (1969) have shown that there is an increase in lethal damage caused by UV and mitomycin $G$ in mouse $L$ cells following caffeine treatments during the interphase period of DNA synthesis. Kihlman et al. (1971) suggest " at least two mechanisms by which methylated oxypurines produce chromosomal aberrations in plants and mammalian cells: (1) a mechanism favoured by low temperatures which results in exchange-type aberrations in cells treated during prophase and $\mathrm{G}_{2}$ and which, at least in plant cells, is dependent on the ATP levcl of the cells and (2) a mechanism favoured by high temperature which results in fragmentation of chromatids in cells treated during the period of DNA synthesis and which is independent of the ATP level in the cells". All inhibitors of DNA synthesis, however, do not increase somatic crossing-over and Vig (1973) suggest it is " not DNA per se but a spccific step in its synthesis, or in the synthesis of protein or some 
related phenomenon, which gives rise to somatic recombination in Glycine max". Complementary chromosomal exchanges following caffeine treatment cannot be due solely to the inhibition of DNA synthesis but additionally to a more specific event in DNA repair, such as an inhibition in the gapfilling process which could lead to an accumulation of gaps in the daughter strands and an increase in chromosomal aberrations.

Single site aberrations could arise from cross-overs in which one component failed to establish a cell lineage; in Antirrhinum this has been seen with some certainty but many of the single sites have doubtless arisen by other means; point mutation, non-disjunction, deficiencies, translocation are obvious possibilities. The number and type of single site aberrations recorded here indicate the many pathways to floral mosaicism although accurate identification of all types is not possible at this stage. Many somatic variants can, however, be identified with some certainty and these could produce viable new plant forms by vegetative propagation. Also, heterozygous material, if repeatedly propagated vegetatively, could be expected to diverge considerably from type. A recent survey of fruits from many apple varieties and seedlings at the John Innes Institute gave abundant evidence for twin-spotting and sectoring that would provide uncontrolled variability if it occurred in the scions used for multiplication.

The ambiguous sectoring behaviour sometimes seen in homozygous pal$r e c$ may result from somatic crossing-over within newly formed heterozygous tissue. A situation could thus occur: pal-rec/pal-rec $\mu--\rightarrow$ pal-rec/pal-carnea $-\rightarrow \rightarrow$ (by crossing-over) pal-rec/pal-rec (component as general background and indistinguishable in flaking intensity) +pal-carnea/pal-carnea (a homozygous unflaked palely pigmented component); or as an additional example, pal-rec/pal-rec $\mu-\rightarrow \rightarrow$ pal-rec/pal-tincta (lower flaking intensity) $-\rightarrow$ (by crossing-over) pal-rec/pal-rec (normal flaking and indistinguishable) + paltincta/pal-tincta (acyanic unflaked component). The observed frequency of unflaked sectors in homozygous pal-rec appears higher than expected and unless some triggering of both pal-rec to mutate simultaneously to the same or similar stable alleles occurs the sectoring behaviour could be an additional manifestation of somatic crossing-over.

Evans and Paddock (1976) have made a comparative study of Glycine max, Nicotiana tabacum, Gossypium barbadense and Lycopersicum esculentum, the four crop species that have provided the most convincing evidence for somatic crossing-over in higher plants. Somatic crossing-over has been calculated by Carlson (1974) to occur spontaneously between the Sulfur marker and the centromere in Nicotiana tabacum at a frequency of $6.7 \times 10^{-5}$ per mitosis in leaf tissue and $4.6 \times 10^{-5}$ per mitosis in in vitro cultured cells. An estimate on the same material by Evans and Paddock was $0.77 \times 10^{-5}$ and for Glycine $\max \left(Y^{11} Y^{11}\right)$ a frequency of $5.74 \times 10^{-5}$. Our tentative estimate for inc/Inc in Antirrhinum majus (from control in caffeine treatment) incorporating several approximations is $0.96 \times 10^{-5}$. The Antirrhinum data provide further evidence for the more general occurence of somatic crossingover, and, in spite of probable differences in gene to centromere distance, at a comparable frequency to that presented for the $S u / s u$ heterozygote in Nicotiana tabacum by Evans and Paddock.

Acknowledgments.-It is a pleasure to record our appreciation to $\mathrm{Mr}$ Tim Hardwick for summer vacational help and to Mr L. S. Clarke for the production of the photographs. 


\section{REFERENCES}

BARROW, J. R., CHAUDhARI, H., AND DUNFORD, M. P. 1973. Twin spots on leaves of homozygous cotton plants. $\mathcal{J}$. Heredity, 64, 222-226.

BARROW, J. R., AND DUNFOKD, M. P. 1974. Somatic crossing-over as a cause of chromosome multi-valents in cotton. $\mathcal{F}$. Heredity, 65, 3-7.

BLIXT, s. 1972. Mutation genetics in Pisum. Agri. Hortique Genetica, 30, 1-293.

CARlson, p. s. 1974. Mitotic crossing over in a higher plant. Genet. Res., 24, 109-112.

GHRISTIANSON, M. L. 1975. Mitotic crossing over as an important mechanism of floral sectoring in Tradescantia. Mutation Res., 28, 389-395.

CUANY, R. L., SPARkow, A. H., AND POND, v. 1958. Genetic response of Antirrhinum majus to acute and chronic plant irradiation. Z. indukt. Abstam. Vererbungsl., 89, 7-13.

Deshayfs, A., AND Dulieu, H. 1974. In Polyploidy and Induced Mutations in Plants, pp. 85-99 International Atomic Energy Agency, Vienna.

DOMAN, M., AND RAUTH, A. M. 1969. Ultraviolet-light irradiation of mouse L cells: effects on cells in the DNA synthesis phase. Radiat. Res., 40, 414-429.

Dulieu, H. L. 1975. Somatic variations on a yellow mutant in Nicotiana tabacum L. $\left(a_{1}+a_{1} a_{2}+/ a_{2}\right)$. II. Reciprocal genetic events occurring in leaf cells. Mutation Res.. $28,69-77$.

DUbinin, N. P., AND NEMTSEVA, L. s. 1969. Chromosome chromatid rearrangements resulting from the mitotic crossing over between sister chromatids in ring chromosomes of Crepis capillaris. Molec. Gen. Genet., 104, 331-338.

EVANS, D. A., AND PADDOGK, E. F, 1976. Comparison of somatic crossing over frequency in Nicotiana tabacum and three other crop species. Can. F. Genet. Cytol., 18, 57-65.

Finchaм, J. k. s. 1970. The regulation of gene mutation in plants. Proc. Roy. Soc. Lond., $B, 174,295-302$.

FINCHAM, J. R. S., AND HARRISON, B. J. 1967. Instability at the pal locus in Antirrhinum majus. II. Multiple alleles produced by mutation of one original unstable allele. Heredity, 22, 211.

GRunererg, H. 1966. The case of somatic crossing-over in the mouse. Genet. Res., 7, 56-75.

Harrison, B. J. 1967. Mutability in Antirrhinum majus. Fohn Innes 58th Annual Report.

HARRISON, B. J., AND GARPENTER, R. 1973. A comparison of the instabilities at the nivea and pallida loci in Antirrhinum majus. Heredity, 31, 309-323.

HARRISON, B. J., AND FINCHAM, J. R. S. 1964. Instability at the pal locus in Antirrhinum majus. I. Effects of environment on frequencies of somatic and germinal mutation. Heredity, 19, 237-258.

HARRISON, B. J., AND FINCHAM, J. R. s. 1965. Crossing-over in the pal linkage group. Fohn Innes 56th Annual Report.

HARRISON, B. J., AND FINCHAM, J. R. S. 1968. Instability at the pal locus in Antirrhinum majus. III. A gene controlling mutation frequency. Heredity, 23, 67.

HARRISON, B. J., AND STICKLAND, R. G. 1974. Precursors and genetic control of pigmentation. II. Genotype analysis of pigment controlling genes in acyanic phenotypes in Antirrhinum majus. Heredity, 33, 112-115.

hendrychova-tomkova, J. 1964. Local somatic colour changes in Salvia splendens. $\mathcal{J}$. Genet., 59, 7-13.

HIRONO, Y., AND RÉDEI, G. P. 1965. Induced premeiotic exchange of linked inarkers in the angiosperm Arabidopsis. Genetics, 51, 519-526.

HOLlidAy, $\mathrm{R}, 1964$. The induction of mitotic recombination by mitomycin $\mathrm{C}$ in Ustilago and Saccharomyces. Genetic, 50, 323-335.

JONES, D. F. 1937. Somatic segregation and its relation to atypical growth. Genetics, 22, 484-522.

knhlman, B. A. (edit.). 1974. Proceedings of the Symposium "Caffeine as an environmental mutagen and the problem of synergistic effects". Mutation Res. (special issue), 26, 51-155.

KIhlMAN, B. A., STURELID, s., NORLÉn, K., AND tidriko, D. 1971. Caffeine, caffeine derivatives and chromosomal aberrations. II. Different responses of Allium root tips and Chinese hampster cells to treatments with caffeine, 8-ethoxycaffeine and 6-methylcoumarin. Hereditas, 69, 35-50.

kUckuaK, н. 1938 . Untersuchungen über Koppelungen bei Antirrhinum majus. VIII. Die Genkarte des Uni-chromosoms. Z.f. indukt.-Abst.u. Vererbungsl., 75, 24-54. 
MCGLINTOCK, в. 1951. Chromosome organisation and genic expression. Cold Spring Harb. Symp. Quant. Biol., 16, 13-47.

MERICLE, L. W., AND MERICLE, R. P. 1967. Genetic nature of somatic mutations for flower colour in Tradescantia, Glone 02. Radiation Bot., 7, 449-464.

MIZUNo, N. s., stoops, C. E., AND sinHA, A. A. 1971. DNA synthesis associated with the inner membrane of the nuclear envelope. Nature, New Biol., 229, 22-24.

NÖTHIGER, R., AND DüBEndorfer, A. 1971. Somatic crossing-over in the housefly. Molec. Gen. Genetics., 112, 9-13.

Ross, J. G., AND holm, G. 1960. Somatic segregation in tomato. Hereditas, 46, 224-230.

SASTry, G. R. K. 1976. Evocation of instability at the Pal locus in Antirrhinum majus. Heredity, 36 (3), 315-329.

SEREBrovsky, A. s. 1925. Somatic segregation in domestic fowl. 7. Genet., 16, 33-42.

STERN, C. 1936. Somatic crossing over and segregation in Drosophila melanogaster. Genetics, $21,625-730$.

STICKLAND, R. G., AND HARRison, B. J. 1974. Precursors and genetic control of pigmentation. I. Induced biosynthesis of pelargonidin, cyanidin and delphinidin in Antirrhinum majus. Heredity, 33, 108-112.

stubbe, н. 1966. Genetik und Zytologie von Antirrhinum L., Sect. Antirrhinum. Fischer, Jena.

VIG, B. K. 1973. Somatic crossing over in Glycine $\max$ (L) Merrill : Effect of some inhibitors of DNA synthesis on the induction of somatic crossing over and point mutations. Genetics, 73, 583-596.

VIG, B. K. 1974. Somatic crossing-over in Glycine $\max$ (L) Merrill: Differential response to ${ }^{3} \mathrm{H}$-emitted $\beta$-particles and ${ }^{60}$ Co emitted $\gamma$-rays. Radiation Botany, 14, 127-137.

VIG, B. K. 1975. Soybean (Glycine $\max$ ) : A new test system for study of genetic parameters as affected by environmental mutagens. Mutation Res., 31, 49-56.

VIG, B. K. AND PADDOCK, E. F. 1970. Studies on the expression of somatic crossing over in Glycine $\max$ L. Theoret. Appl. Genetics, 40, 316-321.

WEBER, A. 1968. The mechanism of the action of caffeine on sarcoplasmic reticulum. 7. Gen. Physiol., 52, 760-772. 